\title{
Super dominant left anterior descending artery with origin of both posterior descending artery and posterior left ventricular artery from septal branch
}

\author{
Soumya Patra, Srinivas BC, Navin Agrawal, Manjunath CN
}

Department of Cardiology, Sri Jayadeva Institute of Cardiovascular Sciences \& Research, Bangalore, Karnataka, India

\section{Correspondence to}

Dr Soumya Patra, dr_soumyapatra@rediffmail. com

\section{DESCRIPTION}

The posterior descending artery (PDA) arises from the right coronary artery (RCA) in approximately $85 \%$ of people in right dominant circulation. Whereas only in $10-15 \%$ of cases, it arises from the circumflex artery (LCX) or from both RCA and LCX. $^{1}$ Rarely the posterior descending artery can arise from the left anterior descending (LAD) coronary artery. ${ }^{23}$ A 65 -year-old man presented with new onset effort angina of Canadian Cardiovascular Society class II severity. He was hypertensive and a smoker. Exercise treadmill test was positive in 9.1 metabolic equivalents of task (METS). Blood investigations revealed only the presence of hyperlipidaemia (low density lipoprotein $141 \mathrm{mg} / \mathrm{dL}$ ). ECG was normal and echocardiography was found to have normal left ventricular ejection fraction with concentric left ventricular hypertrophy with no regional wall motion abnormality. Coronary angiography showed a normal left main coronary artery. LAD artery showed luminal irregularities and it was giving rise to large first septal branch. This first septal branch after its septal course divides into large posterior left ventricular branch (PLV)) and a small PDA. The PDA ends after meeting an ascending branch from LAD in the posterior atrioventricular grove (figures 1 and 2; videos 1 and 2). LCX is giving rise to left atrial circumflex branch and obtuse marginal (OM) branches (figure 2). RCA is

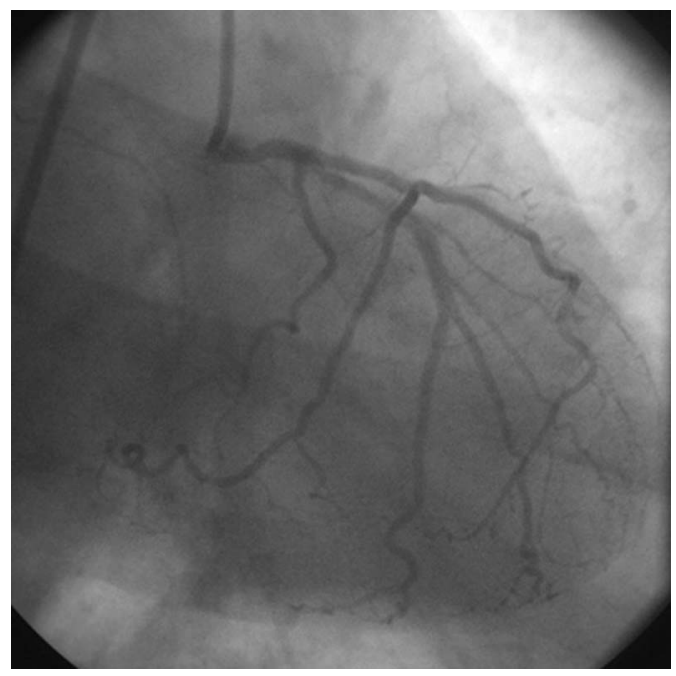

Figure 1 Right anterior oblique view with caudal angulations, showed septal branch of left anterior descending coronary artery is providing posterior descending artery and PLV. Left circumflex artery is only supplying to $\mathrm{OM}$ and left atrial circumflex branches. $\mathrm{OM}$, obtuse marginal; PLV, posterior left ventricular branch.

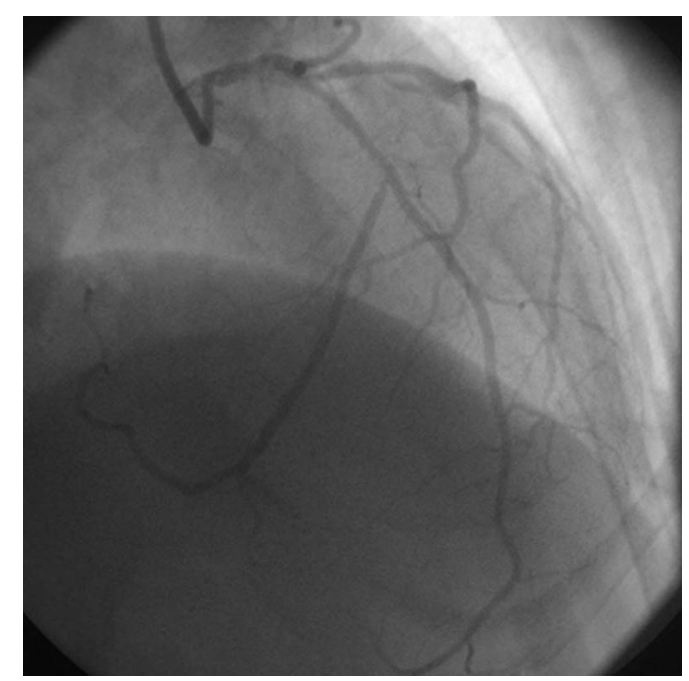

Figure 2 Right anterior oblique view with cranial angulations showed a long PLV and a small posterior descending artery is arising from first septal branch of left anterior descending coronary artery with luminal irregularities. PLV, posterior left ventricular branch.

originated normally from right coronary sinus and found to be non-dominant (figure 3). This anomalous LAD supplied the most of the heart by giving origin of PDA and PLV through septal branch. Though, CT coronary angiogram is the best noninvasive test to detect coronary artery anomalies ${ }^{3}$ but the patient was not willing to undergo.

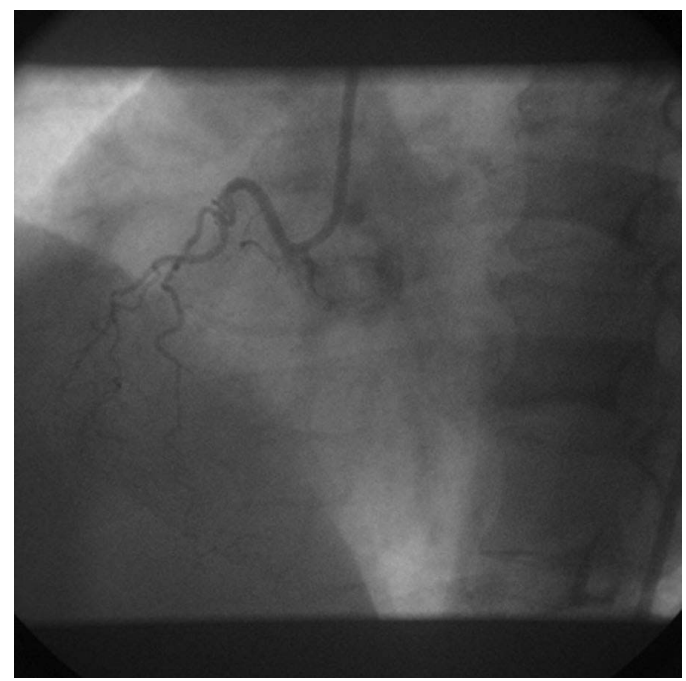

Figure 3 Left lateral view showed non-dominant right anterior oblique. 


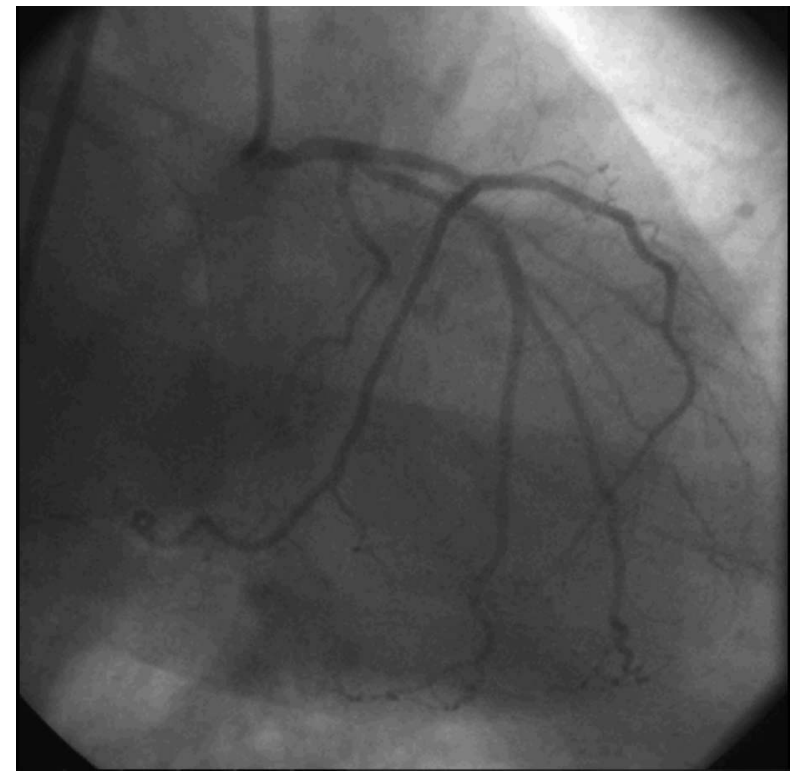

Video 1 Right anterior oblique (RAO) view with caudal angulations, showed septal branch of LAD is providing PDA and PLV. LCX is only supplying to $O M$ and left atrial circumflex branches. $L A D$, left anterior descending; LCX, circumflex artery; OM, obtuse marginal; PDA, posterior descending artery; PLV, posterior left ventricular branch.

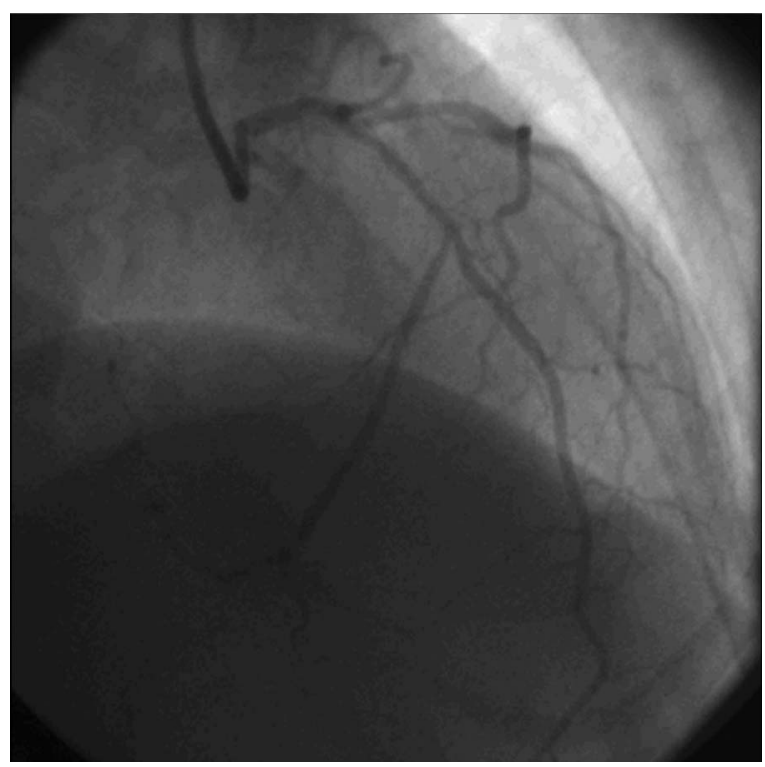

Video 2 Right anterior oblique (RAO) view with cranial angulations showed along PLV and a small PDA is arising from first septal branch of LAD with luminal irregularities. LAD, left anterior descending; PDA, posterior descending artery; PLV, posterior left ventricular branch.

\section{Learning points}

- Coronary artery anomalies have a reported incidence of $0.2-1 \%$ of routine angiographic studies.

- Coronary anomalies are best diagnosed by CT coronary angiogram.

- Rarely, posterior descending artery can arise from left anterior descending coronary artery.

Contributors All authors contributed in the diagnosis and management of this patient.

Competing interests None.

Patient consent Obtained.

Provenance and peer review Not commissioned; externally peer reviewed.

\section{REFERENCES}

1 Javangula K, Kaul P. Hyperdominant left anterior descending artery continuing across left ventricular apex as posterior descending artery coexistent with aortic stenosis. J Cardiothorac Surg 2007;21:42.

2 Ghosh P, Liew CK, Chauhan A. A rare coronary anatomy comprising dual (Type IV) left anterior descending arteries and an anomalous left circumflex artery from the right coronary artery. J Invasive Cardiol 2011;23126-7.

3 Singh SP, Soto B, Nath $\mathrm{H}$. Anomalous origin of posterior descending artery from left anterior descending artery with unusual intraseptal course. J Thorac Imaging 1994;9255-7. 
Copyright 2013 BMJ Publishing Group. All rights reserved. For permission to reuse any of this content visit http://group.bmj.com/group/rights-licensing/permissions.

BMJ Case Report Fellows may re-use this article for personal use and teaching without any further permission.

Become a Fellow of BMJ Case Reports today and you can:

- Submit as many cases as you like

- Enjoy fast sympathetic peer review and rapid publication of accepted articles

- Access all the published articles

- Re-use any of the published material for personal use and teaching without further permission

For information on Institutional Fellowships contact consortiasales@bmjgroup.com

Visit casereports.bmj.com for more articles like this and to become a Fellow 